\title{
ANÁLISE DE NECESSIDADES DE TREINAMENTO EM CALL CENTERS
}

\author{
Sirley de Carvalho \\ sirleycarvalhoback@hotmail.com \\ Universidade Salgado de Oliveira - Niterói, RJ / Brasil \\ Luciana Mourão \\ mourao.luciana@gmail.com \\ Universidade Salgado de Oliveira - Niterói, RJ / Brasil
}

http://dx.doi.org/10.1590/1413-2311.0042013.40564

Recebido em 05/03/2013

Aprovado em 23/06/2014

Disponibilizado em 01/12/2014

Avaliado pelo sistema double blind review

Revista Eletrônica de Administração

Editor: Luís Felipe Nascimento

ISSN 1413-2311 (versão on-line)

Editada pela Escola de Administração da Universidade Federal do Rio Grande do Sul.

Periodicidade: Quadrimestral

Sistema requerido: Adobe Acrobat Reader.

\section{RESUMO}

Os sistemas de atendimento representam o elo entre a organização e os consumidores e, nesse sentido, deveriam ser entendidos como ferramenta estratégica. Porém, a falta de qualificação dos profissionais de call centers é um fato que tem trazido muitas implicações para a vida das pessoas. O primeiro passo para as ações de capacitação consiste na avaliação de suas necessidades de treinamento. Contudo, apesar de a avaliação de necessidades de treinamento influenciar em todo o processo de Treinamento e Desenvolvimento - T\&D, este aspecto ainda tem sido pouco pesquisado. A presente pesquisa objetivou identificar a percepção de necessidades de treinamento de supervisores de call centers e se variáveis pessoais como idade, escolaridade, tempo de serviço, tempo como supervisor e motivação para aprender influenciam nessa percepção de necessidade de treinamento. Participaram do survey 251 supervisores de uma grande empresa de call center e foram realizadas 6 entrevistas em profundidade. Os resultados apontam para: (i) uma baixa percepção de necessidades de capacitação; e (ii) uma predição da motivação para aprender e da percepção de importância e de domínio prévio das competências do curso sobre a percepção de necessidade de treinamento. As variáveis idade, escolaridade, tempo de serviço e tempo como supervisor não figuraram como variáveis preditoras da percepção de necessidades de treinamento. O estudo corrobora outros achados da literatura e aponta contribuições teóricas e metodológicas, além de algumas reflexões que podem ser úteis para os profissionais que atuam na área.

Palavras-Chave: Análise de Necessidade de Treinamento; Call Center; Competências; Motivação para Aprender; Treinamento.

\section{ANALYSIS OF NEED FOR TRAINING IN CALL CENTERS}

\author{
ABSTRACT \\ REAd | Porto Alegre - Edição 79 - N 3 - setembro/dezembro 2014 - p. 740-772
}


The customer service systems are the link between the organization and customers and should be understood as a strategic tool. However, the lack of professional qualification of operators and supervisors of call centers has brought many implications for people's lives. The first step in the training activities consists in assessing the training needs. However, despite the assessment of training needs influence the whole process of Training and Development - T \& $\mathrm{D}$, this aspect has not been well studied yet. This study aimed to identify the perceived training needs of call center supervisors and the possible influence of age, education, length of service time as a supervisor and motivation to learn about the perceived need for training. To that end, it was investigated a sample of 251 supervisors from a company call center and 6 additional interviews were conducted. The results point to the prediction of motivation to learn and also the perception of importance and prior knowledge course on the general perception of training needs. The variables age, education length of service time, and length of service time as a supervisor not figured as predictors of perceived need for training. This study supports other findings in the literature and points theoretical and methodological contributions, and some thoughts that may be useful for professionals who work in personnel management of call centers.

Keywords: Analysis of Training Needs; Call Center; Skills; Motivation to Learn; Training.

\section{ANÁLISIS DE LA NECESIDAD DE ENTREINAMIENTO EN CALL CENTERS}

\section{RESUMEN}

Los sistemas de atención a la población representan el eslabón entre la organización y los consumidores y en este sentido, deberían ser entendidos como una herramienta estratégica. Pero la falta de calificación de los profesionales de los llamados call centers es un hecho que ha traído muchas implicaciones para la vida de las personas. El primer paso para las acciones de capacitación consiste en la evaluación de sus necesidades de entrenamiento. Sin embargo, a pesar de la evaluación de las necesidades de entrenamiento influir en todo el proceso de Entrenamiento y Desarrollo - T\&D, este aspecto aún ha sido poco investigado. Esta investigación objetivó identificar la percepción de las necesidades de entrenamiento de los supervisores de los call centers y ver si variables personales como la edad, escolaridad, tiempo de servicio, tiempo como supervisor y la motivación para aprender influyen en esta percepción de necesidad de entrenamiento. Para esto, fue investigada una muestra de 251 supervisores de una gran empresa de call center, además se realizaron 6 entrevistas. Los resultados apuntan para la baja percepción de las necesidades de capacitación y para la predicación de la motivación para aprender y de la percepción de la importancia y del dominio previo de las competencias del curso sobre la percepción de la necesidad de entrenamiento. Las variables edad, escolaridad, tiempo de servicio y tiempo como supervisor no constan como variables predictoras de la percepción de la necesidad de entrenamiento. El estudio corrobora otros hallazgos en la literatura y apunta contribuciones teóricas y metodológicas, además de algunas reflexiones que pueden ser útiles para los profesionales que actúan en el área.

Palabras Clave: Análisis de la Necesidad de Entrenamiento; Call Center; Competencias; Motivación para Aprender; Entrenamiento. 


\section{INTRODUÇÃO}

Em um mundo de constantes mudanças, as organizações não podem ignorar a importância do desenvolvimento contínuo dos seus empregados frente aos desafios da inovação e da concorrência. A força de trabalho passou a ser vista como vital para os resultados das organizações e compreendida como diferencial competitivo. Nesse contexto, a área de gestão de pessoas tem estado mais atenta para o sistema de Treinamento, Desenvolvimento e Educação - TD\&E. Porém, as pesquisas sobre essa temática não têm conseguido abranger todos os subsistemas de treinamento, sendo visível a baixa produção de pesquisas sobre análise de necessidades de treinamento, tanto na literatura nacional como na internacional (AGUINIS e KRAIGER, 2009; SILVA e MENESES, 2012). Mas, apesar da menor produção no subsistema de Análise de Necessidades de Treinamento - ANT quando comparado a outros subsistemas de treinamento, têm ocorrido frequentes pesquisas de levantamento de necessidades de treinamento em diferentes áreas como Agricultura (OMMANI e CHIZARI, 2009), Saúde (KLEMP, FRAZIER, GLENNON, TRUNECEK e IRWIN, 2011), Educação (ABBAD e MOURÃO, 2010) e Esportes (SANTOS, MESQUITA, GRAÇA e ROSADO, 2010).

No que diz respeito às categorias profissionais, algumas delas demandam um olhar ainda mais cuidadoso em relação às ações de treinamento. Os profissionais que atuam em call centers no Brasil enquadram-se em uma categoria cuja capacitação contínua é visivelmente demandada. As estratégias de conquista e fidelização do cliente se constituem em importantes desafios para administradores e empresários. Os serviços de atendimento ao consumidor são muitas vezes a porta que abre novas possibilidades para as organizações e também a porta pela qual os clientes saem, não raras vezes, em função da insatisfação com os canais de atendimento.

Os estudos internacionais sobre os call centers de atendimento têm focado variáveis relacionadas à lógica de funcionamento das centrais; à produtividade dos teleatendentes e à satisfação e fidelização dos usuários (CHANG e HUANG, 2000) em detrimento de uma preocupação com as condições de trabalho e com as exigências das tarefas (FERREIRA, 2004; VERAS e FERREIRA, 2006). Nesse sentido, é cabível perguntar em que medida os trabalhadores que atuam nos serviços de atendimento estão recebendo a capacitação necessária? Quais os resultados de uma análise de necessidades de treinamento para este 
Sirley de Carvalho \& Luciana Mourão

público? Quais as variáveis que influenciam a percepção que o supervisor de call center tem de sua necessidade de treinamento? Essas são algumas lacunas de conhecimento na área e são importantes porque têm implicações diretas tanto para as organizações de call center como para a sociedade, de modo geral, que é usuária desse tipo de serviço.

Para tentar responder às lacunas identificadas, este estudo tem três objetivos principais: (i) mensurar o quanto os supervisores de call centers percebem que precisam de treinamento (a partir da percepção da importância atribuída à capacitação e do domínio prévio das competências a serem desenvolvidas no mesmo); (ii) investigar a possível relação entre motivação para aprender e percepção de necessidades de treinamento; (iii) investigar a possível influência do tempo de trabalho e da experiência como supervisor na percepção de necessidade de treinamento.

Para atender a esses objetivos foi realizada uma pesquisa com metodologia quantitativa e qualitativa, tendo participado 251 supervisores de uma grande empresa de call center. Os profissionais responderam a um questionário contendo questões sobre características pessoais (idade, tempo de serviço, tempo como supervisor) e escalas de percepção de necessidade de treinamento e de motivação para aprender. Adicionalmente, foram realizadas seis entrevistas em profundidade que trouxeram algumas reflexões importantes para os resultados desta pesquisa.

O artigo foi organizado em cinco seções. A primeira traz o referencial teórico subdividido em Análise de Necessidades de Treinamento e Motivação para Aprender. A seção seguinte é destinada ao Modelo de Pesquisa e Método, onde são especificados as hipóteses investigadas e os procedimentos metodológicos adotados para a verificação das mesmas. A terceira seção destina-se à apresentação dos Resultados, a partir das análises preliminares, das análises descritivas, dos resultados dos testes de hipóteses e da análise de conteúdo das entrevistas. A Discussão dos Resultados é o objeto da próxima seção, na qual os achados da pesquisa são debatidos à luz da literatura científica pertinente à temática. Por fim, são apresentadas as Considerações Finais com as principais conclusões da pesquisa, bem como suas limitações e recomendações.

\section{REFERENCIAL TEÓRICO}

\subsection{Análise de necessidades de treinamento}

REAd | Porto Alegre - Edição 79 - N 3 - setembro/dezembro 2014 - p. 740-772 
Um dos sistemas da área de Gestão de Pessoas para os quais os profissionais conferem maior relevância é o de TD\&E; em função da importância cada vez maior de qualificação e requalificação constantes dos funcionários nas organizações. A capacitação sistematizada é uma necessidade não só das organizações e dos indivíduos, mas também da sociedade (AGUINIS e KRAIGER, 2009).

Borges-Andrade, Abbad e Mourão (2012) apresentam o sistema de treinamento composto por três subsistemas, a saber: análise de necessidades de treinamento; planejamento e implementação; e avaliação de treinamento. De acordo com essa visão, o treinamento seguiria um processo cíclico em que as demandas de desenvolvimento de competências seriam inicialmente investigadas, dando origem ao planejamento e implementação de ações educacionais, as quais serão posteriormente avaliadas, de tal sorte que essa avaliação retroalimenta os processos de análise de necessidades de capacitação e também de planejamento instrucional.

Apesar da reconhecida importância dessa etapa de diagnóstico das necessidades de treinamento (AGUINIS e KRAIGER, 2009; LIMA e BORGES-ANDRADE, 2006), essa é uma das áreas pouco estudadas neste campo (AGUINIS e KRAIGER, 2009; SALAS e CANNON-BOWERS, 2001). Isso precisa ser mudado porque eventuais falhas na avaliação de necessidades repercutem negativamente nos dois outros subsistemas de treinamento, uma vez que há uma relação de interdependência entre os mesmos.

A etapa de avaliação das necessidades de treinamento é, portanto, o principal ponto para se estabelecer relações entre a execução do treinamento e seus resultados, uma vez que é nessa etapa em que são tomadas as decisões sobre quais serão as ações de TD\&E, quem será treinado e sobre qual enfoque (FERREIRA, ABBAD, PAGOTTO e MENESES, 2009). A ANT pode ser definida, portanto, como um processo sistemático de coleta, análise e interpretação de dados relacionados a discrepâncias de competências em três níveis: organizacional, de tarefas e individual. Tal processo destina-se ao desenho, planejamento, execução e avaliação de cursos.

A ANT com foco no desenvolvimento e na aprendizagem tem por objetivo fornecer oportunidades de crescimento para a pessoa no contexto da organização (McCLELLAND, 1993). A prática de ANT visa ao alinhamento entre o negócio organizacional e as competências individuais (MENESES e ZERBINI, 2009) e pode ser definida como processos que objetivam diagnosticar hiatos de competências dos indivíduos, de modo que os mesmos

REAd | Porto Alegre - Edição 79 - N 3 - setembro/dezembro 2014 - p. 740-772 
possam ser transformados em objetivos instrucionais (ABBAD; FREITAS; BORGESANDRADE e PILATI, 2006). Em definição semelhante, Clarke (2003) sentencia que a ANT refere-se ao processo organizacional de coleta e análises de dados que subsidiam a tomada de decisão acerca de quando o treinamento é a melhor opção para aprimorar o desempenho de indivíduos, bem como para definir quem deve ser treinado e qual conteúdo deve ser ministrado.

Vale observar que as definições apresentadas consideram a ANT como um processo e que todas falam em um diagnóstico baseado em coleta e análise de dados que irão nortear as ações futuras de TD\&E. Porém, observa-se que Clarke (2003) rotula tal processo como “organizacional” e, segundo o autor, os modelos atuais de ANT têm uma visão unitarista e racional das organizações, ignorando a influência das relações sociais e das dinâmicas organizacionais nas tomadas de decisão sobre treinamento. Nesse sentido, vale dizer que a visão sobre ANT precisa ser expandida.

Considerando a relevância do nível macro de análise, Meneses e Zerbini (2009) sugerem que a prática de ANT seja iniciada pela análise organizacional e argumentam que evitar essa etapa implica maior probabilidade de fracasso da ação de capacitação. Assim, depois de realizada a análise organizacional, deve-se passar para a definição dos outputs demandados de cada uma das áreas, departamentos ou unidades de negócio. Determinados os principais outputs, então, são definidos os Conhecimentos, Habilidades e Atitudes (CHAs) necessários. Uma vez cumpridas todas essas etapas, chega o momento de realizar a análise individual requerida para o sucesso do processo de ANT (MENESES e ZERBINI, 2009).

De maneira sintética poder-se-ia dizer que a ANT corresponde à identificação do que um empregado ou um grupo tem que aprender, no sentido de preencher a lacuna existente entre a situação presente e o nível de êxito desejado. A respeito de tal definição, vale dizer que: o desempenho esperado para o momento atual não necessariamente será o mesmo em um momento futuro, ou seja, não basta identificar as lacunas atuais de desempenho, também é necessário traçar o perfil de funcionário que será necessário num tempo futuro determinado, uma vez que as tarefas e as competências são mutantes.

Em termos teóricos, a estrutura predominante para considerar a necessidade de treinamento continua a ser a categorização de análise organizacional, análise de tarefas e análise individual propostas por McGehee e Thayer (1961). A análise organizacional tem como propósito inicial proporcionar informações sobre onde e quando o treinamento é 
necessário em uma organização. A análise de tarefas identifica a natureza das tarefas a serem executadas no trabalho e os CHAs necessários para o desempenho das mesmas. Por fim, a análise individual visa identificar quem deve ser treinado e que treinamento é necessário para cada um.

Na revisão de literatura apresentada por Salas e Cannon-Bowers (2001), sobre as pesquisas de treinamento na década de 1990, os autores constatam forte evolução da área, mas reconhecem que, no que diz respeito à análise de necessidades de treinamento, ainda há muito a avançar. Na mesma linha, Aguinis e Kraiger (2009) também constatam o aumento do investimento nas pesquisas sobre avaliação de treinamento e um foco bem menor para a análise de necessidades de treinamento, concluindo que o subsistema de ANT ainda precisa de mais investigação e atenção dos pesquisadores e profissionais.

As pesquisas empíricas nacionais sobre ANT têm avançado nas últimas décadas. Entre os estudos da área podem ser citados alguns. A ANT foi associada à gestão de carreiras, ampliando o conceito de carreira e mostrando o quanto o mesmo está ligado a constantes ações de capacitação e aprendizagem (SULLIVAN e BARUCH, 2009). Outra pesquisa objetivou levantar as necessidades de treinamento de agricultores colonos e de suas mulheres, a partir da abordagem denominada de papel ocupacional (MENEZES, RIVERA e BORGESANDRADE, 1988). Houve também um estudo para desenvolver a ANT, porém com foco na inclusão do levantamento de atitudes que demandavam capacitação (MAGALHÃES e BORGES-ANDRADE, 2001).

Na literatura da área foi localizada uma análise sistemática das necessidades de treinamento na Empresa Brasileira de Pesquisa Agropecuária - Embrapa, com levantamento das características e funcionamento de cada setor e de seus cargos, comparação das tarefas prescritas e o trabalho real, análise de cargo e incidentes críticos e posterior aplicação individual de um instrumento a todos os empregados, com estabelecimento de índices de prioridade geral de necessidades de treinamento (ROCHA, LEAL e ABBAD, 2002).

Encontrou-se também um estudo cujo objetivo foi diagnosticar necessidades de treinamento, com base em competências esperadas no papel ocupacional tanto em relação às demandas globais presentes na organização, quanto em relação às demandas específicas ou localizadas, com um rigoroso método desenvolvido em dez etapas sequenciais, desde o contato com as chefias dos setores até a elaboração de relatório de necessidades de treinamento, passando por pesquisa documental e bibliográfica, entrevistas com análise de 
conteúdo e aplicação in loco do instrumento de mensuração (CASTRO e BORGESANDRADE, 2004).

Tem-se ainda o trabalho de Bruno-Faria e Pena-Brandão (2003) que apresentaram uma pesquisa quantitativa (survey) e qualitativa (análise de documentos, entrevistas e técnicas de brainstorming e brainwriting) que teve como objetivo principal elaborar um instrumento destinado a identificar competências profissionais relevantes a profissionais de TD\&E de uma organização pública do Distrito Federal. Em conjunto, esses estudos mostram o interesse pela temática, ao mesmo tempo em que evidenciam que há ainda poucas pesquisas nacionais sobre ANT e que os investimentos sobre as mesmas precisam aumentar.

\subsection{Motivação para aprender}

Para iniciar o processo de treinamento, os participantes devem estar preparados para aprender e motivados para iniciar esse processo. A motivação para o treinamento pode ser compreendida como "direção, intensidade e persistência do comportamento direcionado para aprender em contextos de treinamento” (COLQUIT; LEPINE e NOE, 2000, p. 678).

A importância da motivação do aprendiz no processo de aprendizagem e de transferência para o trabalho em relação ao que foi aprendido é fundamental (GAGNÉ, 1985). Alguns estudos sugerem que os aspectos motivacionais relacionados ao treinamento deveriam ser examinados sob a perspectiva da Teoria de Expectância apresentada por Vroom (1964), que é baseada na ideia de que o indivíduo formula expectativas cognitivas a respeito de efeitos decorrentes de seus próprios comportamentos e do valor relativo que atribui a cada um desses efeitos. Desse modo, o treinamento tem um valor particular para o indivíduo porque é uma ferramenta ou instrumento para o alcance de outros resultados, como promoção ou aumento de salário.

De acordo com Vroom (1964), a Teoria da Expectância é uma teoria cognitiva de processo, que aborda um modelo multiplicativo: Valência versus Instrumentalidade versus Expectância. O referido modelo sugere que a motivação de uma pessoa para tomar uma decisão decorre simultaneamente dessas três variáveis: (i) valência (o quanto um indivíduo deseja uma recompensa, considerando o nível de satisfação que a pessoa espera receber e não o valor da recompensa em si); (ii) expectância (estimativa de que o seu reforço resultará no esperado); e (iii) instrumentalidade (estimativa de que determinado desempenho seja um

REAd | Porto Alegre - Edição 79 - N 3 - setembro/dezembro 2014 - p. 740-772 
caminho adequado para chegar a uma recompensa ou a probabilidade que liga um desempenho a uma determinada recompensa almejada).

As teorias da Expectância e do Estabelecimento de Metas são consideradas por Gondim e Silva (2004) como teorias de processo, sendo a motivação humana entendida como um processo de tomada de decisão em que estão em jogo as percepções, os objetivos, as expectativas e as metas pessoais. No presente estudo, será adotado como modelo teórico geral a Teoria da Expectância de Vroom (1964), sendo especificamente pesquisada a variável de motivação para aprender. A Figura 1 resume o modelo de Vroom (1964), considerado para a presente pesquisa.

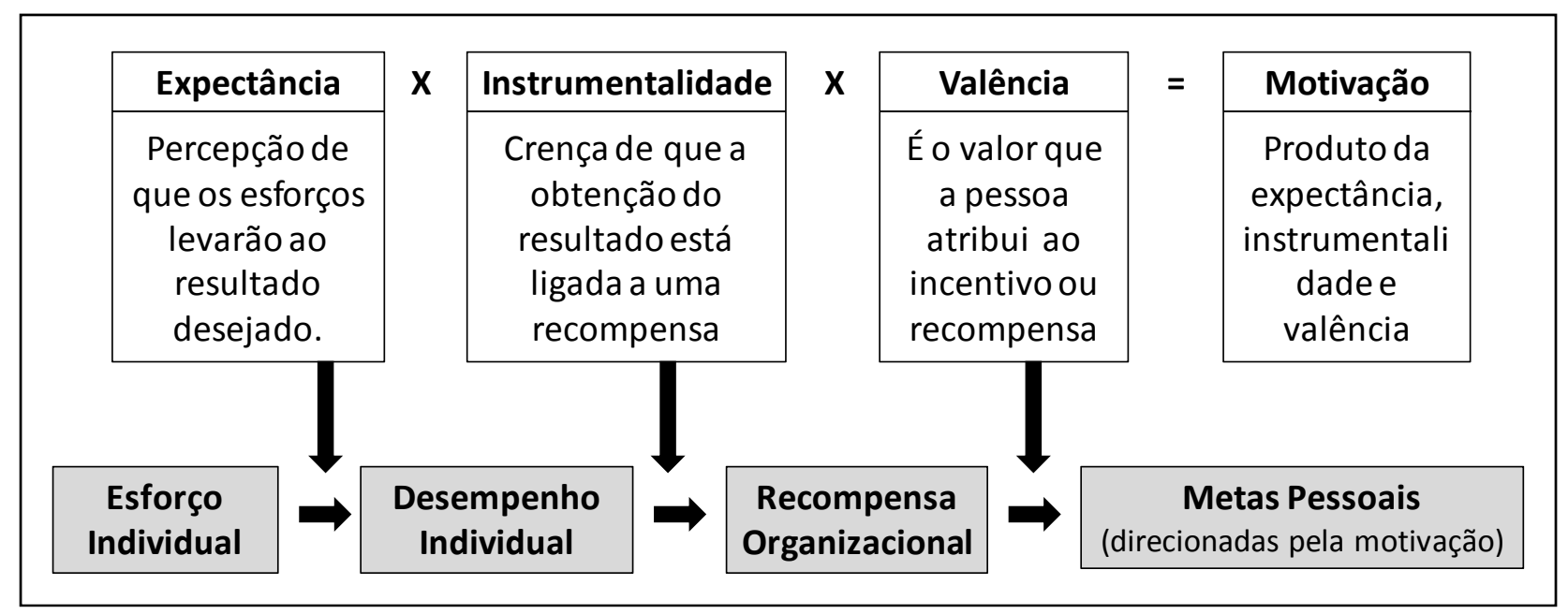

Figura 1 - Modelo motivacional de Vroom (1964) Fonte: elaborado pelas autoras, 2013.

Diferentes pesquisas têm buscado compreender o papel exercido pela motivação do treinando em diferentes momentos do treinamento e relacioná-la com diversos resultados do treinamento, como satisfação com o evento instrucional, aprendizagem, transferência do treinamento, entre outros (PILATI, 2004). A seguir serão brevemente relatados alguns desses estudos.

A literatura traz uma metanálise das pesquisas na área com um modelo hipotético, que considera a motivação para aprender como preditora direta de resultados de aprendizagem e de transferência e desempenho no trabalho mediado por aprendizagem (COLQUIT ET AL., 2000). Os autores relataram que as variáveis: personalidade, idade e fatores situacionais têm

REAd | Porto Alegre - Edição 79 - N 3 - setembro/dezembro 2014 - p. 740-772 
relação de moderada a forte com motivação para aprender e também com a autoeficácia, prétreinamento e a valência atribuída ao evento instrucional. A motivação no modelo dos autores seria preditora de alguns dos resultados de aprendizagem.

Outro estudo avaliou se a motivação para aprender e a motivação em função da expectativa de recompensas explicam a menor ou maior participação em ações de TD\&E. Os resultados demonstraram que: (i) a motivação para o treinamento não é variável mediadora dos efeitos de suporte organizacional na participação das ações de TD\&E; (ii) o suporte organizacional prediz mais a participação em ações de treinamento em empregados com alta motivação do que em empregados com baixa motivação; e (iii) a motivação para o treinamento explica moderadamente a participação nessas ações (THARENOU, 2001).

Uma pesquisa buscou investigar os fatores mediadores entre a atribuição e a motivação do treinamento, ou seja, se a importância percebida pelos empregados em relação ao programa de TD\&E seria uma variável que media o relacionamento entre a atribuição do treinamento e a motivação para o mesmo. Os resultados suportaram a hipótese e mostraram que, comparados àqueles que participavam voluntariamente do treinamento, os que estavam no evento por imposição da chefia tiveram motivação mais elevada (TSAI e TAI, 2003).

Outro estudo demonstra que a motivação do participante após o treinamento tem uma relação maior com o resultado do treinamento em curto prazo. Assim, à medida que o treinado distancia-se do evento instrucional, o resultado passa a ser cada vez mais controlado pelo ambiente de trabalho (SALLORENZO, 2000).

O exame dos efeitos das reações dos treinandos com a motivação para aprender foi feito em uma pesquisa, que considerou três dimensões de reações, distribuídas em justiça e utilidade, influência da motivação no treinamento e eficácia total do treinamento. O estudo mostrou que as percepções de distribuições na justiça são relacionadas positivamente à motivação para aprender e que esta se relaciona positivamente às reações do treinamento, à autoeficácia pós-treinamento, e às intenções de comportamento (BELL e FORD, 2007).

Por fim, Mourão e Marins (2010) investigaram a motivação para aprendizagem em ações de treinamento e concluíram que: (i) o tempo de trabalho influencia na motivação para o treinamento, sendo que os mais novos apresentam mais motivação para aprender; e (ii) instrutores externos estão associados a uma maior motivação para aprender.

REAd | Porto Alegre - Edição 79 - N 3 - setembro/dezembro 2014 - p. 740-772 


\section{MODELO DE PESQUISA E MÉTODO}

Considerando a revisão de literatura e as lacunas identificadas na mesma, foram, então, formuladas três hipóteses, derivadas diretamente dos objetivos de pesquisa, a saber:

Hipótese 1: As características pessoais de idade, tempo de serviço, tempo como supervisor serão preditoras da percepção de necessidade de treinamento, sendo que pessoas mais jovens, com menos tempo de trabalho e menor tempo na função de supervisão tenderão a perceber maior necessidade do treinamento oferecido;

Hipótese 2: A motivação para aprender é preditora da percepção de necessidade de treinamento, sendo que pessoas com maior motivação para aprender tenderão a perceber maior necessidade do treinamento oferecido; e

Hipótese 3: A importância atribuída ao treinamento e o domínio prévio das competências que serão alvo das ações de capacitação são preditoras da percepção de necessidades de treinamento, sendo que pessoas com maior percepção de importância e menor percepção de domínio tenderão a perceber maior necessidade do treinamento oferecido. Com base nessas hipóteses, apresenta-se na Figura 2 o modelo de pesquisa que foi investigado.

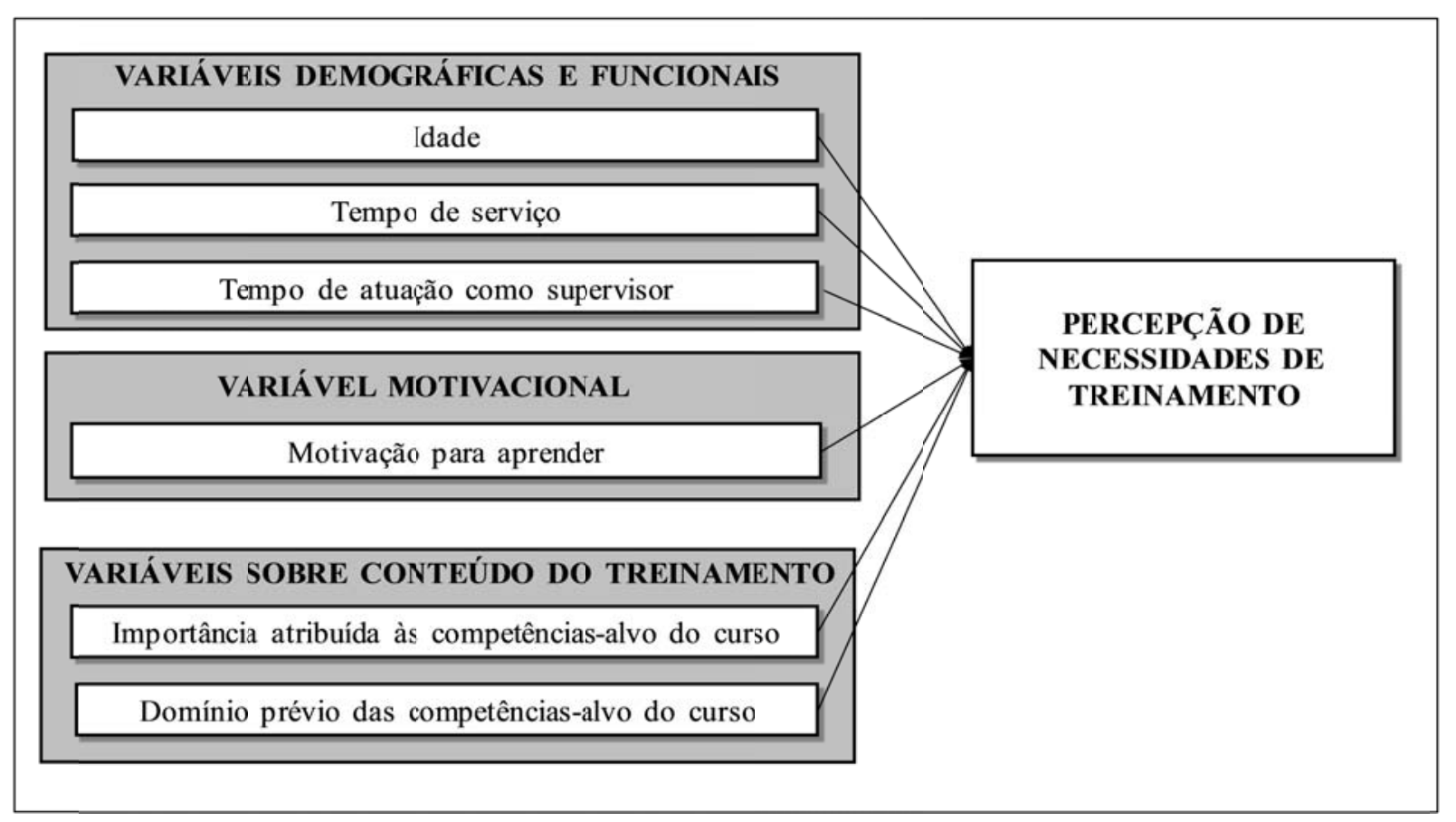

Figura 2 - Modelo inicial de pesquisa Fonte: elaborado pelas autoras, 2013.

REAd | Porto Alegre - Edição 79 - N 3 - setembro/dezembro 2014 - p. 740-772 


\subsection{Participantes}

O universo da pesquisa foi uma empresa de grande porte, com mais de 2.000 funcionários, que atua na área de call center. Os sujeitos da pesquisa foram os 302 supervisores e trainees que participaram de treinamentos. Em 2010 houve um levantamento da empresa para identificar os CHAs que seriam desenvolvidos nos cursos. Os dados relativos à avaliação desses treinamentos foram coletados nos anos de 2011 a 2013. A etapa quantitativa da pesquisa foi planejada para ser censitária, pois todos os participantes da capacitação receberam o questionário. A taxa de retorno foi de 83\%, totalizando uma amostra de 251 pessoas (o que, a um intervalo de confiança de 95\%, resulta em margem de erro de 2,5\%). Foi também realizada uma etapa qualitativa de pesquisa na qual foram ouvidos seis profissionais de call centers, sendo três do sexo masculino e três do feminino, com idades variando de 20 a 27 anos e tempo de atuação na área entre um e quatro anos. Esta etapa qualitativa teve a função de complementar os resultados encontrados na etapa quantitativa, dando voz às pessoas que supervisionam call centers e que participam de treinamentos.

Quanto ao perfil dos participantes da etapa quantitativa, a idade média dos respondentes foi de 30 anos (desvio padrão de oito anos), sendo a maior parte do sexo masculino (53\%), com praticamente a metade dos respondentes de nível médio (49\%), mas com expressivo percentual de graduados (42\%). O tempo total de trabalho variou de 1 a 38 anos, com média de três anos e meio (desvio padrão de cinco anos), enquanto o tempo médio na função de supervisor foi de 2,5 anos (desvio padrão de quatro anos) e variação de 1 a 23 anos na função. O resumo do perfil do público-alvo pesquisado é apresentado na Tabela 1.

Tabela 1 - Dados Descritivos sobre os Participantes ( $\mathrm{N}=251)$

\begin{tabular}{cc}
\hline Sexo & $\mathbf{\%}$ \\
\hline Feminino & 47,3 \\
\hline Masculino & 52,7 \\
\hline Escolaridade & $\mathbf{\%}$ \\
\hline Ensino médio & 49,2 \\
\hline Ensino superior & 42,0 \\
\hline Pós-graduação & 8,8 \\
\hline Tempo de trabalho (anos) & $\mathbf{M ~ ( D P )}$ \\
\hline Tempo total de trabalho & $3,6(4,7)$ \\
\hline Tempo de trabalho como supervisor & $2,5(4,0)$ \\
\hline
\end{tabular}

Fonte: elaborado pelas autoras, 2013.

REAd | Porto Alegre - Edição 79 - N 3 - setembro/dezembro 2014 - p. 740-772 


\subsection{Instrumento de coleta de dados}

A coleta de dados foi realizada por intermédio de questionário (etapa quantitativa) e roteiro semiestruturado (etapa qualitativa). O roteiro continha cinco questões abertas sobre o trabalho em call center e sobre as oportunidades de participação em ações de treinamento, incluindo a percepção de necessidades de capacitação e a motivação para aprender.

O questionário utilizado no survey era caracterizado por questões quantitativas de duas escalas distintas. A Escala de Levantamento de Necessidades de Treinamento foi construída, utilizando-se o método adotado por Borges-Andrade e Lima (1983), também adotada nas pesquisas de Castro e Borges-Andrade (2004) e Abbad e Mourão (2010). De acordo com esse método, os itens do questionário são associados a duas escalas Likert de quatro pontos: uma de Importância ( 0 = Sem importância e 3 = Muito Importante) e outra de Domínio ( 0 = Sem Domínio e 3 = Domínio Completo).

Para o cálculo da necessidade de treinamento foram listadas oito competências resultantes do diagnóstico de necessidades de desenvolvimento profissional, realizado pela empresa responsável pelo call center, o qual foi feito a partir dos seguintes passos: (i) análise da estratégia organizacional contemplando: missão, visão, valores, objetivos e competências essenciais para o alcance das metas; (ii) descrição das atividades funcionais relativas ao cargo de supervisor com a participação dos treinandos que listaram suas atividades diárias; (iii) realização de entrevistas com o público-alvo do curso, na qual os pesquisados relataram as tarefas que tinham mais dificuldades e também as que desempenhavam com maior facilidade; (iv) atribuição de pesos junto aos principais gestores da organização para definição daquelas que eram consideradas competências mais relevantes para serem contempladas no curso.

Como resultado desse processo, foram listadas oito competências correspondentes ao conteúdo programático do curso (capacidade analítica, negociação, liderança, comunicação, relacionamento interpessoal, conhecimento técnico, capacidade de realização e equilíbrio emocional). Para cada uma, os pesquisados teriam que atribuir uma avaliação relativa à importância daquela competência para a realização do seu trabalho (Escala de Importância do Curso), bem como uma avaliação do quanto ele já tinha domínio daquela mesma competência (Escala de Domínio Prévio do Conteúdo do Curso).

A partir da aplicação dessas duas escalas foi calculado o indicador de necessidade, a partir da fórmula proposta por Borges-Andrade e Lima (1983): $\mathrm{N}=\mathrm{i} \times(\mathrm{e}-\mathrm{d})$, onde: $\mathrm{N}=$ 
necessidade; i = importância; d = domínio; e = valor extremo ou máximo da escala utilizada. Nesse indicador, as necessidades de capacitação são definidas operacionalmente como o produto da percepção de importância das competências pela percepção de ausência de domínio das mesmas. Portanto, quanto menor o domínio e maior a importância da competência, maior será a necessidade de treinamento. Em sentido inverso, também é válido dizer que avaliações de alto domínio e de baixa importância resultam na ausência de necessidade de capacitação.

A análise fatorial para a escala de Análise de Necessidades de Treinamento apontou estrutura de fator único, a qual conseguiu explicar 34,8\% da variância. O índice de fidedignidade da escala foi ficou dentro de padrões satisfatórios (Alpha de Cronbach = 0,73) e as cargas fatoriais variaram de 0,52 a 0,66, sinalizando que a medida tende a ser estável.

A Escala de Motivação para Aprender foi desenvolvida originalmente por Warr, Allan e Birdi (1999), traduzida para o português e analisada por Lacerda e Abbad (2003), sendo um ano depois analisada novamente por Pilati (2004). Esse instrumento permite identificar se os participantes se sentem motivados para aprender os conteúdos de programas de treinamento. A versão da escala em português possui cinco itens (p.e.: Geralmente eu fico entusiasmado para aprender coisas novas; Costumo evitar as oportunidades de aprendizagem), associados a uma escala concordância, com estrutura unifatorial e coeficiente de fidedignidade (Alfa de Cronbach) de 0,75 (LACERDA e ABBAD, 2003). No presente estudo, confirmou-se a mesma estrutura, sendo que o fator extraído explica 64\% da variância, as cargas fatoriais ficaram acima de 0,60 e o Alpha de Cronbach foi de 0,88, o que evidencia as qualidades psicométricas dessa escala para a amostra utilizada.

\subsection{Procedimentos de Coleta de Dados}

A empresa de call center autorizou formalmente a realização desta pesquisa e a mesma foi aprovada por um comitê de ética. Cada participante recebeu os e-mails das responsáveis pela pesquisa para tirar qualquer dúvida e para ter acesso aos resultados da pesquisa, caso fosse de seu interesse.

Não houve estabelecimento de amostra para a etapa quantitativa, porque a pesquisa teve caráter censitário; sendo distribuídos questionários a todos os que participaram da ação de treinamento especificada. Para a etapa qualitativa, a amostra foi de conveniência, sendo

REAd | Porto Alegre - Edição 79 - N 3 - setembro/dezembro 2014 - p. 740-772 
pesquisados seis profissionais que atuam em call centers. Em ambas as etapas da pesquisa, houve acesso direto aos sujeitos pesquisados e a todos foi garantido o sigilo das respostas individuais. Todos os pesquisados assinaram o termo de consentimento livre e esclarecido.

\section{RESULTADOS}

O tratamento dos dados quantitativos foi feito por meio do software SPSS, versão 19.0 com as seguintes análises estatísticas: (i) limpeza do banco de dados; (ii) análises descritivas; (iii) correlação; e (iv) regressão linear padrão. Em relação aos dados qualitativos, foi feita análise de conteúdo categorial (Bardin, 1977; Bauer, 2010), que se caracteriza como procedimento de fragmentação de textos com o objetivo de identificar regularidades. Os resultados dessas análises são detalhados a seguir.

\subsection{Análises preliminares}

Para checar a adequação do tamanho da amostra para regressão foram utilizadas as duas fórmulas de Green (1991) apresentadas por Tabachinick e Fidel (2007), sendo o tamanho adequado segundo as duas fórmulas: (1) $50+8$ vezes o número de variáveis independentes (50 + 8 x 5 = 90); e (2) 104 + o número de variáveis independentes $(104+5=109)$. Como a amostra foi superior a 200 respondentes, esse critério foi atendido.

Na primeira etapa da análise foi feita a limpeza do banco de dados para identificar a presença de dados omissos (missing values). Foram identificados 1,5\% de valores faltosos considerando as respostas às escalas. Como os casos faltosos foram poucos e assistemáticos, optou-se pela sua substituição pela média.

As distribuições univariadas também foram examinadas por meio de métodos gráficos (boxplot) e numéricos (medidas de simetria), com o objetivo de avaliar: (i) normalidade; (ii) homogeneidade de variância; (iii) presença de dados extremos (outliers), sejam univariados (Distribuição Z), sejam multivariados (Distância Mahalanobis). Algumas variáveis tiveram que ser transformadas. O critério numérico utilizado para avaliar a necessidade de transformações foi ancorado na simetria. Variáveis foram transformadas sempre que o escore $\mathrm{Z}$ para simetria (simetria/erro padrão de medida da simetria) foi maior que 1,96 (HAIR ET AL., 2009; Tabachnick; Fidell, 2007). Foi necessário efetuar dois tipos de transformações nas

REAd | Porto Alegre - Edição 79 - N 3 - setembro/dezembro 2014 - p. 740-772 
variáveis: a raiz quadrada para a variável análise de necessidade de treinamento e o inverso do logaritmo ao quadrado para a variável motivação para aprender. Essas transformações resolveram satisfatoriamente os problemas de simetria, de curtose e de heterogeneidade de variância.

Após as transformações, foi identificado um outlier univariado na variável necessidade de treinamento, o qual foi excluído das análises. As demais variáveis não apresentaram anomalias dignas de nota. Em relação aos outliers multivariados, foram identificados dez casos no total (4\% da amostra total), sendo também excluídos das análises. As variáveis transformadas foram utilizadas em todas as análises de correlação e regressão. Para clarificar a interpretação dos resultados, são apresentadas as médias e os desvios padrão das variáveis antes da transformação (Tabachnick; Fidell, 2007).

Para possibilitar que fosse feita a análise de regressão também foram avaliadas a multicolinearidade e a análise de resíduos. A análise de resíduos mostrou que a distribuição dos mesmos é regular, sem identificação de variância constante (homocedasticidade) ou de correlação entre os erros. Em relação à multicolinearidade, foi encontrada alta correlação entre as variáveis: Tempo de Trabalho e Tempo de Trabalho como Supervisor $(r=0,72)$. Vale esclarecer que tal correlação já era esperada, devido à natureza de tais variáveis. Contudo, o teste de colinearidade não apresentou valores de VIF acima de cinco e nem valores de tolerância baixo de 0,1 , e o condition index indicou que tais variáveis não apresentariam problemas de colinearidade se ficassem juntas como variáveis independentes.

\subsection{Análises descritivas}

A análise de necessidade de treinamento foi feita a partir de duas variáveis: uma escala de necessidade de treinamento (de zero a nove), que lista as competências profissionais a serem desenvolvidas no curso (análise de necessidade específica de treinamento); e uma declaração do grau de percepção de necessidade do referido curso por parte dos participantes, em uma escala de zero a dez (análise de necessidade geral de treinamento). Ambas as medidas foram aplicadas antes da realização do curso.

No cálculo da necessidade de treinamento, a partir do método adotado por BorgesAndrade e Lima (1983), tem-se uma média mais alta de percepção de necessidade de treinamento para as competências: conhecimento técnico, capacidade de realização e 
equilíbrio emocional (médias entre 5,4 e 5,7, numa escala de zero a nove). Por outro lado, as competências comunicação e relacionamento interpessoal foram as que tiveram médias de percepção de necessidade de capacitação mais baixas 1,6 e 1,3, respectivamente. Por fim, como competências cujas demandas seriam intermediárias (mas também baixas), têm-se: a capacidade analítica, a negociação e a liderança (médias entre 2,3 e 2,4). A variável necessidades de treinamento em geral teve média de 7,9 (DP = 2,21), em uma escala de zero a dez, indicando uma percepção, de moderada a elevada, da necessidade do referido treinamento. A Tabela 2 mostra as médias relativas à variável necessidade do treinamento.

Tabela 2 - Dados Descritivos da Percepção de Necessidade de Treinamento

\begin{tabular}{|c|c|c|c|}
\hline Tipo de Medida & Itens pesquisados na ANT & Média & $\begin{array}{c}\text { Desvio } \\
\text { padrão }\end{array}$ \\
\hline $\begin{array}{l}\text { Análise de necessidade } \\
\text { geral de treinamento } \\
\text { (escala de } 0 \text { a 10) }\end{array}$ & Competências gerenciais em geral & 7,9 & 2,21 \\
\hline \multirow{8}{*}{$\begin{array}{l}\text { Análise de necessidades } \\
\text { específicas de treinamento } \\
\text { (escala de } 1 \text { a } 9)\end{array}$} & Capacidade Analítica & 2,4 & 1,74 \\
\hline & Negociação & 2,4 & 1,94 \\
\hline & Liderança & 2,3 & 1,80 \\
\hline & Comunicação & 1,6 & 1,50 \\
\hline & Relacionamento Interpessoal & 1,3 & 1,41 \\
\hline & Conhecimento Técnico & 5,9 & 1,63 \\
\hline & Capacidade de Realização & 5,7 & 1,58 \\
\hline & Equilíbrio Emocional & 5,4 & 1,67 \\
\hline
\end{tabular}

Fonte: elaborado pelas autoras, 2013.

Os resultados mostram que a percepção de necessidades específicas de treinamento tendeu a ser menor do que a percepção de necessidade geral de treinamento. Isto significa que quando se pergunta sobre a necessidade do curso de forma global, os participantes tendem a perceber como algo mais necessário do que quando se pergunta a eles a necessidade de uma a uma das competências que seriam desenvolvidas durante o curso.

Vale salientar que, de modo geral, houve uma percepção bastante baixa da necessidade de capacitação por parte dos supervisores de call centers, pois considerando uma escala de nove pontos, em cinco das oito competências avaliadas, a média foi igual ou inferior a 2,4 (ou seja, bem abaixo da média aritmética da escala que seria 4,5). Em relação aos desvios padrão

REAd | Porto Alegre - Edição 79 - N 3 - setembro/dezembro 2014 - p. 740-772 
Sirley de Carvalho \& Luciana Mourão

dessas variáveis, os mesmos não foram muito elevados, variando de 1,4 a 1,9 para as variáveis de nove pontos e 2,2 para a escala de 11 pontos, indicando heterogeneidade moderada das respostas.

Em relação à motivação para aprender, a média da escala foi bastante elevada 6,3 (DP=0,94), numa escala que variava de um a sete, indicando uma distribuição bastante assimétrica e com desvio à direita. Nesse sentido, os dados mostram uma percepção alta da motivação para aprender.

\subsection{Resultados dos testes de hipóteses}

Para identificar se havia relação entre as variáveis, idade, tempo de serviço, escolaridade, tempo de supervisor e motivação para aprender com a percepção de necessidade de treinamento, foi feita análise de correlações bivariadas de Pearson (Tabela 3) entre as possíveis variáveis independentes com a variável dependente, a qual foi medida de duas formas (geral e específica). A única correlação significativa encontrada foi da variável motivação para aprender com a necessidade geral de treinamento $(r=0,34)$, caracterizando-se como correlação de magnitude moderada, de acordo com a classificação de Miles e Shevlin (2001).

Tabela 3 - Correlações das Variáveis do Modelo com a Percepção de Necessidade de Treinamento

\begin{tabular}{lccccc}
\hline Variáveis & $\begin{array}{c}\text { Tempo de } \\
\text { trabalho }\end{array}$ & $\begin{array}{c}\text { Tempo como } \\
\text { supervisor }\end{array}$ & Escolaridade & $\begin{array}{c}\text { Motivação } \\
\text { para } \\
\text { aprender }\end{array}$ & $\begin{array}{c}\text { Necessidade } \\
\text { geral de } \\
\text { treinamento }\end{array}$ \\
\hline Idade & $0,42^{* *}$ & $0,34^{* *}$ & 0,12 & $-0,01$ & $-0,08$ \\
\hline Tempo de trabalho & & $0,72^{* *}$ & $0,29 * *$ & $-0,13$ & $-0,08$ \\
\hline Tempo como supervisor & & 0,14 & $-0,08$ & $-0,09$ \\
\hline Escolaridade & & & 0,00 & 0,03 \\
\hline Motivação para aprender & & & & $0,34^{* *}$ \\
\hline
\end{tabular}

Fonte: elaborado pelas autoras, 2013.

Os dados mostram que a percepção de necessidade geral de treinamento teria relação exclusivamente com a motivação para aprender. Porém, uma análise separada dos resultados das escalas de importância e domínio das competências que eram objeto do curso avaliado mostra que a importância está relacionada significativamente à percepção de necessidade geral de treinamento $(\mathrm{r}=0,21, \mathrm{p}<0,01)$, enquanto o domínio dos conteúdos não apresenta correlação significativa $(r=0,08, p=0,24)$ com tal percepção de necessidade (Tabela 4).

REAd | Porto Alegre - Edição 79 - N 3 - setembro/dezembro 2014 - p. 740-772 
Tabela 4 - Correlações com as Variáveis Importância e Domínio das Competências do Treinamento e com a Percepção de Necessidade de Treinamento

\begin{tabular}{llccc}
\hline \multicolumn{1}{c}{ Variáveis } & Importância & Domínio & $\begin{array}{c}\text { Necessidade geral } \\
\text { de treinamento }\end{array}$ & $\begin{array}{c}\text { Necessidades } \\
\text { especificas de } \\
\text { treinamento }\end{array}$ \\
\hline Idade & & & $-0,08$ & $-0,08$ \\
\hline Tempo de trabalho & 0,02 & 0,10 & $-0,08$ & $-0,14$ \\
\hline Tempo como supervisor & 0,08 & 0,20 & $-0,09$ & $-0,08$ \\
\hline Escolaridade & 0,03 & 0,13 & 0,03 & 0,03 \\
\hline Motivação para aprender & 0,11 & 0,05 & $0,34^{* *}$ & 0,06 \\
\hline $\begin{array}{l}\text { Necessidade geral de } \\
\text { treinamento }\end{array}$ & 0,35 & $0,16^{*}$ & 1,00 & $0,22^{* *}$ \\
\hline
\end{tabular}

Fonte: elaborado pelas autoras, 2013.

A regressão confirmou a existência de relação entre percepção de necessidade geral de treinamento, motivação para aprender e percepção de importância das competências. A variável percepção de domínio das competências também apresentou relação com a percepção de necessidade geral de treinamento, possivelmente pela correlação que a mesma apresenta com a variável percepção de importância das competências $(r=0,30)$ e com a motivação para aprender $(r=0,16)$. Contudo, essa relação foi negativa, pois quanto maior o domínio prévio que a pessoa tem nas competências que serão trabalhadas no curso, menor a percepção de necessidade que ela terá daquele treinamento. A Tabela 5 apresenta os resultados da regressão linear padrão e a Figura 3, traz o modelo final de pesquisa para a variável percepção de necessidade geral de treinamento.

Tabela 5 - Regressão Múltipla Padrão para a Variável Percepção de Necessidade de Treinamento

\begin{tabular}{lccc}
\hline \multicolumn{1}{c}{ Variáveis } & $B$ & $\beta$ & $s r^{2}$ \\
\hline Constante & 24,84 & & 18,50 \\
\hline Idade & $-0,18$ & $-0,05$ & 0,31 \\
\hline Tempo de trabalho & 0,04 & 0,01 & 0,70 \\
\hline Tempo como supervisor & $-0,37$ & $-0,04$ & 0,97 \\
\hline Escolaridade & 6,99 & 0,15 & 3,60 \\
\hline Motivação para aprender & $0,47 * *$ & 0,33 & 0,11 \\
\hline Importância das competências & $14,30 *$ & 5,90 \\
\hline Domínio das competências & $13,73^{*}$ & 5,26 \\
\hline Média $=7,90 \quad \mathrm{DP}=2,21$ & $\mathrm{~F}=6,88$ & $-0,20$ & \\
$\mathrm{R}=0,49$ & $\mathrm{R} 2$ ajustado=0,21 & & \\
\hline$* \mathrm{p}<0,05 ; * * \mathrm{p}<0,01$ & & &
\end{tabular}

Fonte: elaborado pelas autoras, 2013.

REAd | Porto Alegre - Edição 79 - N 3 - setembro/dezembro 2014 - p. 740-772 


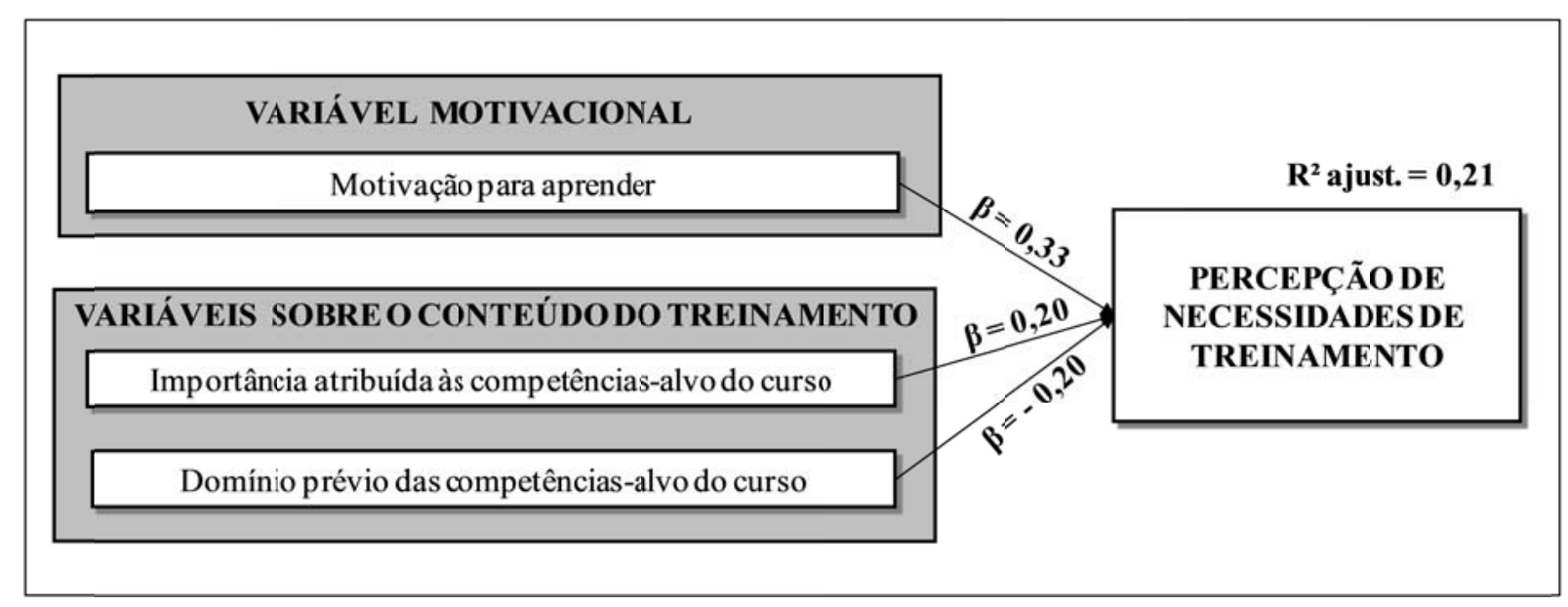

Figura 3 - Modelo final de pesquisa

Fonte: elaborado pelas autoras, 2013.

\subsection{Resultados da análise de conteúdo}

A análise de conteúdo foi feita a partir do agrupamento de elementos de significados mais próximos, com formação de categorias (análise categorial). Assim, a partir da leitura inicial (leitura flutuante) foram anotadas impressões advindas do conteúdo das falas (précategorias). Uma releitura detalhada dos depoimentos levou à construção de grades de categorias contendo tema geral, palavras e frases relacionadas a esse tema.

Os resultados da etapa qualitativa ajudam a explicar alguns resultados obtidos na etapa quantitativa, na medida em que rellacionam a motivação para aprender e a análise de necessidades de treinamento. Vale, contudo, alertar para o fato de que os dados derivados das entrevistas complementam os que foram obtidos na etapa quantitativa, não podendo ser generalizados para a população-alvo, tendo em vista a própria natureza do método qualitativo.

A análise de conteúdo categorial resultou em um conjunto de quatro categorias e nove subcategorias. A Figura 4 mostra a síntese dos resultados desta análise de conteúdo temática, apontando as categorias e subcategorias, bem como a recorrência de cada uma delas (informação entre parênteses após o nome de cada categoria ou subcategoria).

REAd | Porto Alegre - Edição 79 - N 3 - setembro/dezembro 2014 - p. 740-772 


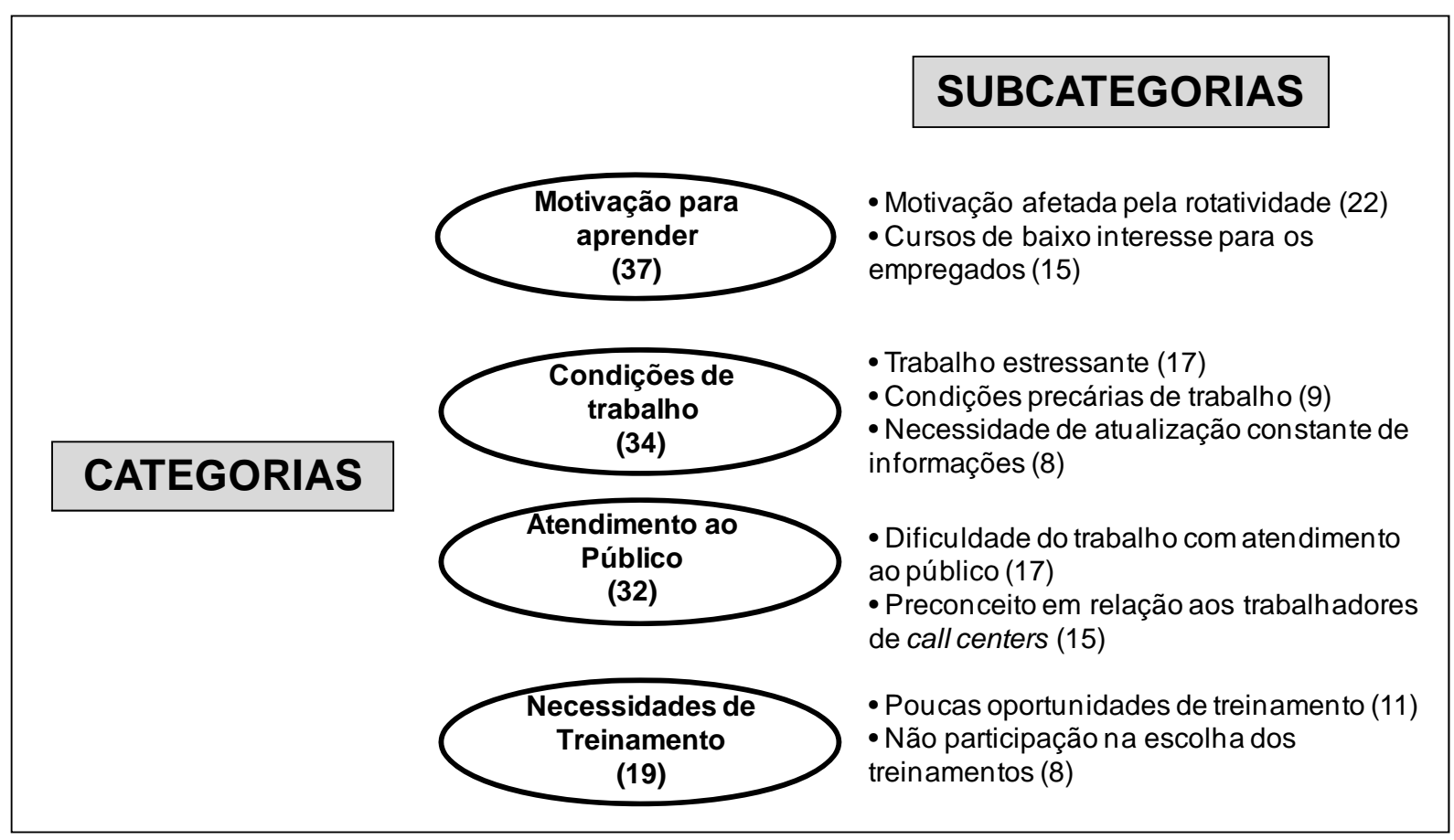

Figura 4 - Resultados da análise de conteúdo categorial Fonte: elaborado pelas autoras, 2013.

A categoria Motivação para aprender foi a mais recorrente nos depoimentos dos pesquisados, tendo sido citada 37 vezes (uma média de seis citações por entrevistado). Nessa temática eles abordaram, sobretudo, o fato de a Motivação ser afetada pela rotatividade (22 citações) e também o oferecimento de Cursos de baixo interesse para os empregados (15 citações). Alguns depoimentos relativos a essa categoria exemplificam o quanto as organizações de call centers precisam rever seus processos de avaliação de necessidades de treinamento:

- “Às vezes no seu primeiro dia você já tem que aprender muita coisa e o treinamento é só ficar olhando o que o colega responde. Não tem, assim, um tipo de curso assim, que ajude mais a gente, que seja mais interessante, entendeu?” (Mulher, 20 anos, um ano de atuação em call center).

- "Eu não sei, acho que o pessoal não fica muito motivado pra aprender, tipo assim, pra aprender coisas novas sobre o trabalho, porque os treinamentos são um pouco cansativos, entendeu? Assim, não são muito legais, entendeu?” (Homem, 24 anos, três anos de atuação em call center).

- "Não sei se vale muito a pena darem treinamento, porque as pessoas não ficam aqui muito tempo, o atendente sempre tenta conseguir um emprego melhor e vai embora. Talvez por isso que tem mais treinamento para o supervisor, porque a gente fica um pouco mais na empresa. Tem supervisor com 15 anos de empresa.” (Homem, 20 anos, dois anos de atuação em call center).

REAd | Porto Alegre - Edição 79 - Nº 3 - setembro/dezembro 2014 - p. 740-772 
Sirley de Carvalho \& Luciana Mourão

- “Tem treinamento, mas o problema é que tem muita rotatividade. Toda hora tem funcionário novo, então, fica até difícil de treinar e fica difícil também do próprio funcionário querer aprender, por causa disso, do entra e sai da empresa.” (Mulher, 27 anos, quatro anos de atuação em call center).

As Condições de Trabalho foram mencionadas como um aspecto que dificulta a motivação para aprender e mesmo a motivação para o trabalho em empresas de call center. Nessa temática, os entrevistados concentraram os depoimentos em três tópicos que deram origem às subcategorias: Trabalho estressante (17 citações), Condições precárias de trabalho (nove citações) e Necessidade de atualização constante de informações (oito citações). A seguir são apresentados alguns depoimentos-chave que ilustram as respostas a esta categoria:

- “O trabalho do atendente é estressante, não tem como não ser. É muito barulho, muita voz falando no seu ouvido, muita informação. É muito cansativo, é um tipo de trabalho que cansa.” (Mulher, 20 anos, um ano de atuação em call center).

- "O funcionário reclama porque as condições de trabalho são ruins, ele fica muito tempo sentado, tem pouco espaço e é muito ruído, muito barulho mesmo. No fim do expediente a pessoa já está muito cansada.” (Homem, 25 anos, dois anos de atuação em call center).

- “É um trabalho muito controlado. Tudo é gravado, você não pode errar nunca. É muita pressão, muita cobrança e o salário nem sempre compensa isso tudo. Então, a gente tem que fazer um esforço muito grande para motivar o funcionário.” (Mulher, 22 anos, dois anos de atuação em call center).

- "Quem trabalha com call center tem que estar aberto a aprender coisas novas, porque é muita informação, cada dia é uma informação diferente e o atendente tem que saber para poder responder. São muitos planos, muita promoção nova, muito procedimento para a pessoa saber informar”. (Homem, 24 anos, três anos de atuação em call center).

A categoria relativa ao Atendimento ao Público, embora não fosse alvo de nenhuma pergunta específica, recebeu muitos comentários (32). As pessoas entrevistadas falaram sobre a Dificuldade do trabalho com atendimento ao público (17 citações) e também sobre o Preconceito em relação aos trabalhadores de call centers (15 citações). Na opinião dos pesquisados, o atendimento ao público é um serviço que demanda motivação para aprender, mas o preconceito é algo que desestimula os profissionais que atuam nesta área. Os depoimentos que se seguem ilustram as opiniões:

REAd | Porto Alegre - Edição 79 - N 3 - setembro/dezembro 2014 - p. 740-772 
- "Eu às vezes entendo quando um atendente se irrita. Quando eu era operador eu me irritava com o cliente, mas eu não deixava ele perceber isso. No atendimento ao público, todo mundo se irrita, porque nem todo mundo tem educação, tem muito cliente que xinga, fala palavrão e você tem que ouvir, então, chega uma hora que isso irrita e a motivação para o trabalho fica menor." (Homem, 20 anos, dois anos de atuação em call center).

- "Quer dizer, tem muita gente que tem preconceito com pessoas que trabalham em central de atendimento. Pensam que todo SAC é igual. Tem muita piada sobre isso, como se livrar de um atendente, coisas assim, como se todo atendente fosse burro e não soubesse dar informação. Isso desestimula quem trabalha em SAC, porque não é verdade, mas tem, tipo assim, muito... muito... preconceito mesmo, sabe?” (Mulher, 27 anos, quatro anos de atuação em call center).

Por fim, na categoria relativa às Necessidades de Treinamento, que foi a menos citada (19 vezes, cerca de três citações por pesquisado), emergiram duas subcategorias, a saber: Poucas oportunidades de treinamento (11 citações) e Não participação na escolha dos treinamentos (oito citações). Os depoimentos apontam para oportunidades escassas de capacitação no trabalho e para processos de diagnóstico de necessidades que não levam em conta as demandas dos trabalhadores:

- “Aqui quase não tem treinamento. Tem muita informação, muita coisa que o atendente precisa saber para dar a informação para os clientes, mas não tem assim treinamento para preparar para esse tipo de trabalho.” (Mulher, 22 anos, dois anos de atuação em call center).

- “Quando vem uma pergunta que o operador não sabe responder nem sempre tem alguém para tirar dúvida. Falta mais treinamento até para a gente poder atender melhor o cliente.” (Homem, 24 anos, três anos de atuação em call center).

- "Nunca participei de nenhuma pesquisa assim sobre as necessidades de treinamento dos meus funcionários e nem mesmo das minhas. A participação da gente nisso é muito pequena, praticamente não existe.” (Homem, 25 anos, dois anos de atuação em call center).

\section{DISCUSSÃO DOS RESULTADOS}

A literatura científica indica que diagnósticos e pesquisas sobre as necessidades de formação têm um caráter ad hoc (MCGEHEE e THAYER, 1961; WEXLEY, 1984; OSTROFF e FORD, 1989; CLARKE, 2003; FERREIRA ET AL., 2009). Nesse sentido, a discussão dos resultados obtidos no que diz respeito às necessidades de treinamento REAd | Porto Alegre - Edição 79 - N 3 - setembro/dezembro 2014 - p. 740-772 
identificadas precisa considerar o contexto no qual a pesquisa foi realizada, que no presente caso compreende os serviços de call center.

A baixa qualidade dos serviços prestados por call centers das mais diversas áreas bancos, cartões de crédito, serviços de telefonia, provedores de internet, TV por assinatura, companhias aéreas etc. - é uma questão cada vez mais presente na sociedade brasileira, tendo inclusive sido motivo de criação de um decreto recente (Decreto $N^{\circ} 6.523$, de 31/07/2008) para proteger os consumidores.

Tem se tornado comum a queixa de entrar em contato com o serviço de atendimento ao consumidor, gastar um tempo excessivo nesse processo e terminar as ligações sem ter conseguido resolver os problemas com a empresa. Muitos clientes se ressentem da baixa qualificação dos atendentes e da baixa autonomia que eles têm para apresentar soluções.

É preciso considerar que o call center é uma parte estratégica do negócio das empresas que o utilizam, independentemente de ele ser parte integrante da estrutura da empresa ou terceirizado. Nesse sentido, os call centers necessitam do processo de levantamento das necessidades de treinamento e de ações de capacitação dos funcionários para que possam ser alcançados os objetivos estabelecidos pelas empresas (VASCONCELLOS, 2010).

Por outro lado, são muitos os estudos que mostram a insatisfação dos trabalhadores que atuam em serviços de atendimento do consumidor e os processos de sofrimento e adoecimento no trabalho que eles enfrentam (FERREIRA, 2004; VILELA e ASSUNÇÃO, 2004; VERAS e FERREIRA, 2006; MOCELIN e SILVA, 2008; SCOLARI; COSTA e MAZZILLI, 2009). Essa categoria profissional demanda, portanto, um olhar atento daqueles que atuam em psicologia organizacional e do trabalho.

A respeito das hipóteses apresentadas neste estudo, observa-se que a Hipótese 1 foi refutada. Ela previa que as características pessoais de idade, tempo de serviço, tempo como supervisor seriam preditoras da percepção de necessidade de treinamento. Na verdade, não se encontrou nenhuma relação entre as variáveis pessoais a percepção de necessidades do treinamento.

A Hipótese 2 foi confirmada, pois a motivação para aprender configurou-se como preditora da percepção de necessidade de treinamento, sendo que supervisores de call center com maior motivação para aprender tenderam a perceber maior necessidade do treinamento oferecido.

REAd | Porto Alegre - Edição 79 - N 3 - setembro/dezembro 2014 - p. 740-772 
A Hipóteses 3 também foi confirmada, pois a percepção da importância das competências do curso e a percepção do domínio dessas competências influenciaram na percepção de necessidade de treinamento (quanto maior a percepção de importância e quanto menor a percepção de domínio prévio, maior foi a percepção de necessidade geral do treinamento).

Avalia-se que este estudo apresente validade interna, porque pode oferecer importantes subsídios para a gestão de pessoas da maior empresa de call center do país (que foi a organização onde os dados foram coletados). Além disso, avalia-se que o estudo também apresente validade externa, pois o perfil do público-alvo pesquisado (trabalhadores jovens, de ambos os sexos, escolarizados ou em processo de escolarização) coincide com a descrição de trabalhadores dessa categoria profissional em pesquisas realizadas em outras localidades (MOCELIN e SILVA, 2008), o que permite supor que os resultados possam também ser relevantes para outras empresas do ramo.

As análises descritivas acerca da análise de necessidade de treinamento apontam para uma percepção elevada da importância dos conteúdos que fariam parte do curso, porém, em algumas dessas competências (relacionamento interpessoal, capacidade de realização, conhecimento técnico, equilíbrio emocional e comunicação), os pesquisados já se sentiam moderadamente qualificados, o que permite um questionamento da pertinência dessas competências no curso, não obstante a importância a elas atribuída.

Uma possibilidade para a explicação da percepção mais baixa das necessidades específicas de treinamento pode estar na dificuldade do público-alvo em identificar os treinamentos de que necessita. Esse resultado vai ao encontro dos achados de Bowman e Wilson (2008), que compararam as percepções de necessidade de treinamento de gestores de uma grande empresa de ônibus com dois grupos externos: gestores em formação e consultores em treinamento. A análise dos resultados desses três grupos mostrou que pessoas com mais habilidade na leitura de relatório estão mais aptas a identificarem as reais necessidades de treinamento e concatenar informações estratégicas de caráter prospectivo.

Nesse sentido, considerando a baixa qualificação profissional do público-alvo da presente pesquisa, é provável que os treinandos tenham uma capacidade reduzida de perceber suas reais necessidades de treinamento, na linha do que foi encontrado por Bowman e Wilson (2008). O fato de escolaridade e idade não explicarem a percepção de necessidade de 
treinamento pode se dever ao tipo de tarefa realizada por essas pessoas, que não permite um crescimento profissional expressivo, conforme sinalizado por Mocelin e Silva (2008).

O fato de o tempo como supervisor e o tempo de serviço também não fazerem diferença para a percepção de necessidades de treinamento é um resultado preocupante, pois, conforme sinalizado por Scolari, Costa e Mazzilli (2009), os supervisores de call center desempenham aspecto decisivo para o trabalho dos atendentes. Nesse sentido, seria desejável que o tempo na função estivesse relacionado ao desenvolvimento de competências profissionais.

Os resultados relativos à motivação para aprender, por outro lado, apontam para uma média elevada, indicando que esse público tem disposição para a aprendizagem, a despeito da baixa qualidade de trabalho. Resultados de outras pesquisas com trabalhadores de baixa escolaridade, como a realizada por Mourão e Marins (2010) também apontam para uma motivação para aprender elevada. Isso pode sinalizar que esse público-alvo anseia por oportunidades de desenvolvimento profissional.

\section{CONSIDERAÇÕES FINAIS}

Considerando a revisão da literatura apresentada, os três objetivos desta pesquisa eram (i) mensurar o quanto os supervisores de call centers percebem que precisam de treinamento; (ii) investigar a possível relação entre motivação para aprender e percepção de necessidades de treinamento; (iii) investigar a possível influência do tempo de trabalho e da experiência como supervisor na percepção de necessidade de treinamento.

Os objetivos propostos puderam ser atendidos com a realização da pesquisa e os resultados obtidos permitem concluir que, para os supervisores de call center:

i. A importância da capacitação muitas vezes é baixa, sobretudo quando são mensuradas necessidades de desenvolvimento de competências relacionadas a atitudes;

ii. Eles já têm domínio das competências específicas que eram alvo da capacitação ofertada;

iii. Características pessoais de escolaridade, idade, tempo de serviço e tempo como supervisor não predizem a percepção de necessidade de treinamento;

REAd | Porto Alegre - Edição 79 - N 3 - setembro/dezembro 2014 - p. 740-772 
iv. A motivação para aprender é preditora da percepção de necessidade geral de treinamento, sendo que pessoas mais motivadas tendem a perceber maior necessidade do treinamento;

v. As percepções de importância do treinamento e de domínio prévio das competências alvo da capacitação predizem a percepção de necessidade geral de treinamento, sendo que quanto maior a importância atribuída às competências e menor a percepção de domínio prévio das mesmas, maior será a percepção de necessidade daquele treinamento.

Esses resultados permitem viabilizar uma solução para a compreensão do problema de pesquisa, pois evidenciam variáveis associadas ou não à percepção de necessidade de capacitação. Assim, os profissionais que atuam na gestão de pessoas de call centers, considerando as variáveis preditoras da presente pesquisa, podem criar programas que desenvolvam a motivação para aprender, bem como estratégias de divulgação interna que mostrem a importância do treinamento, aumentando a probabilidade de sucesso desses eventos.

Além dessa contribuição para os profissionais que atuam na área, a presente pesquisa apresenta também contribuição teórica, pois seus resultados apontam para variáveis preditoras da percepção de necessidade de treinamento ainda não encontradas em outras pesquisas. Vale registrar ainda que, conforme sinalizado por Salas e Cannon-Bowers (2001), Aguinis e Kraiger (2009) e Silva e Meneses (2012), o subsistema de análise de necessidades de treinamento apresenta lacunas e carece de mais pesquisas, sobretudo no que diz respeito a modelos preditivos, que apontem variáveis antecedentes das necessidades de capacitação. Igualmente, o uso de diferentes medidas para a análise de necessidades de treinamento (necessidades específica e necessidade geral) contribui com a discussão metodológica sobre a mensuração dessa variável.

Em relação às limitações da presente pesquisa, é preciso considerar que a mesma restringiu-se à coleta de dados em uma única empresa de call center ainda que tenha sido uma empresa de grande porte e com atuação nacional. Outra limitação refere-se ao fato de terem sido pesquisados apenas os supervisores e trainees, sendo interessante realizar estudos que englobassem também os atendentes de tais organizações.

Para pesquisas futuras, sugere-se a realização de estudos de ANT em trabalhadores de call center, que levem em consideração outras bases de dados, por exemplo, as queixas mais 
frequentes dos usuários, uma vez que o diagnóstico com base na estratégia organizacional e no levantamento com o próprio público-alvo da capacitação mostrou-se insuficiente para traçar as competências que de fato precisam ser desenvolvidas nas ações de capacitação.

Outra sugestão seria a de investigar em que medida a percepção de necessidade de treinamento influencia o impacto do treinamento no trabalho, uma vez que a visão sistêmica de TD\&E pressupõe relações integradas entre os seus subsistemas. Porém, seria importante pesquisar não apenas ANT e impacto, mas também o subsistema de planejamento e execução de treinamento, uma vez que muitas das falhas e os acertos que podem originar o impacto podem estar relacionados a este subsistema.

Também se sugere para pesquisas futuras que seja adotada a abordagem multinível (KOSLOWSKI, BROWN, WEISSBEIN, CANNON-BOWERS e SALAS, 2000; HOX, 2010; HOX e ROBERTS, 2011) que ainda tem sido pouco utilizada para conceber e testar modelos de ANT. Não há dúvida que há ainda muito a se pesquisar e que, não obstante os relevantes avanços constatados nas pesquisas na área de treinamento, segue presente um conjunto de lacunas que demandam mais pesquisas científicas e também maior interação entre pesquisadores e profissionais.

\section{REFERÊNCIAS}

ABBAD, G. S.; MOURÃO, L. Competências profissionais e estratégias de qualificação e requalificação. In: BASTOS, A.V.B.; GONDIM, S.M.G. (Ed) O trabalho do psicólogo no Brasil. Porto Alegre: Artmed, 2010, p. 380-401.

ABBAD, G. S.; FREITAS, I. A.; BORGES-ANDRADE, J. E.; PILATI, R. Medidas de Impacto de TD\&E no trabalho e nas organizações. In: BORGES-ANDRADE, J.E.; ABBAD, G.S.; MOURÃO, L. (Ed). Treinamento, desenvolvimento e educação em organizações e trabalho: fundamentos para gestão de pessoas. Porto Alegre: Artmed, 2006, p. 489-504.

AGUINIS, H.; KRAIGER, K. Benefits of Training and Development for Individuals and Teams, Organizations, and Society. Annual Review of Psychology. Palo Alto, CA, v. 60, n. 1, p. 451-474, 2009.

BARDIN, L. Análise de Conteúdo. Lisboa. Portugal: Edições 70, 1977. 
BAUER, M. W. Análise de conteúdo clássica: uma revisão. In: BAUER, M. W.; GASKELL, G.. Pesquisa Qualitativa com Texto: Imagem e Som: um Manual Prático. Petrópolis: Vozes, 2010, p. 189-217.

BELL, B. S.; FORD, J. K. Reactions to skill assessment: The forgotten factor in explaining motivation to learn. Human Resource Development Quarterly, New York: John Wiley \& Sons, v. 18, n. 1, p. 33-62, 2007.

BORGES-ANDRADE, J.E.; ABBAD, G. S.; MOURÃO, L. Modelos de avaliação e aplicação em TD\&E. In: ABBAD, G. ET AL. (Ed) Medidas de Avaliação em Treinamento, Desenvolvimento e Educação. Porto Alegre: Artmed, 2012, p. 20-35.

CASTRO, P.M.R.; BORGES-ANDRADE, J.E. Identificação das necessidades de capacitação profissional: o caso dos assistentes administrativos da Universidade de Brasília. Revista de Administração Mackenzie, São Paulo, v.39, n.1, p.96-108, 2004.

BORGES-ANDRADE, J.E.; LIMA, S.M.V. Avaliação de necessidades de treinamento: um método de análise do papel ocupacional. Tecnologia Educacional, Rio de Janeiro, v.12, n 54, p. 6-22, 1983.

BOWMAN, J.; WILSON, J. P. Different roles, different perspectives: perceptions about the purpose of training needs analysis. Industrial and Comercial Training, Newcastle upon Tyne, NE, v. 40, n.1, p. 38-41, 2008.

BRUNO-FARIA, M.F.; PENA-BRANDÃO, H. Competências relevantes a profissionais da área de T\&D de uma organização pública do Distrito Federal. Revista de Administração Contemporânea, Curitiba, v.7, n.3, p.35-56, 2003.

BRASIL. Decreto $N^{o} 6.523$, de 31/07/2008. Regulamenta a Lei no 8.078, de 11 de setembro de 1990, para fixar normas gerais sobre o Serviço de Atendimento ao Consumidor - SAC. Brasília - DF, 2008.

CHANG, Z. Y.; HUANG, L. H. Quality deployment for the management of customer calls. Managing Service Quality, Bedford, v. 10, n. 2, p. 98-102, 2000.

CLARKE, N. The Politics of Training Needs Analysis. Journal of Workplace Learning. Bradford: MCB University Press, v. 15, n. 4, p. 141-153, 2003.

COLQUITT, J.A.; LEPINE, J.A.; NOE, R.N. Toward an integrative theory of training motivation: a meta-analytic path analysis of 20 years of research. Journal of Applied Psychology, Washington, DC, v. 85, n. 5, p. 678-707, 2000.

REAd | Porto Alegre - Edição 79 - N 3 - setembro/dezembro 2014 - p. 740-772 
Sirley de Carvalho \& Luciana Mourão

FERREIRA, M. C. Interação teleatendente-teleusuário e custo humano do trabalho em central de teleatendimento. Revista Brasileira de Saúde Ocupacional, São Paulo, v. 29, n.110, p. 715, 2004.

FERREIRA, R. R.; ABBAD, G. S.; PAGOTTO, C. P.; e MENESES, P. P. M. Avaliação de necessidades organizacionais de treinamento: $O$ caso de uma empresa latino-americana de administração aeroportuária. REAd - Revista Eletrônica de Administração, Porto Alegre, v. 15, n. 2, p. 1-26, 2009.

GAGNÉ, R. M. The conditions of learning and theory of instruction (4 $4^{\text {th }}$ ed.). New York: Holt, Rinchardt and Winston, 1985.

GONDIM, S. M. G.; SILVA, N. Motivação no trabalho. In: Zanelli, J. C.; Borges-Andrade, J. E; Bastos, A. V. B. (Ed) Psicologia, organizações e trabalho. Porto Alegre: Artmed, 2004, p. 145-176.

HAIR JR., J.F.; BLACK, W.C.; BABIN, B.J.; ANDERSON, R.E.; TATHAM, R.L. Análise multivariada de dados. (6 $6^{\mathrm{a}}$ ed.). Porto Alegre: Bookman, 2009.

HOX, J. J. Multilevel Analysis: techniques and applications. (2 ${ }^{\text {nd }}$ ed.). New York: Routledge, 2010.

HOX J. J.; ROBERTS J. K. Handbook of advanced multilevel analysis. New York, NY: Routlrdge, 2011.

KLEMP, J.R.; FRAZIER, L.M.; GLENNON, C.; TRUNECEK, J.; IRWIN, M. Improving Cancer Survivorship Care: Oncology Nurses' Educational Needs and Preferred Methods of Learning. Journal of Cancer Education, New York, v. 26, p. 234-242, 2011.

KOSLOWSKI, S. W. J.; BROWN, K.; WEISSBEIN, D.; CANNON-BOWERS, J.; SALAS, E. A Multilevel Approach to Training Effectiveness: Enhancing Horizontal and Vertical Transfer. In: KLEIN, K.; KOSLOWSKI, S. W. J. (Eds.), Multilevel Theory, Research and Methods in Organization. San Francisco: Jossey-Bass, 2000, p. 157-210.

LACERDA, E. R. M.; ABBAD, G. S. Impacto do treinamento no trabalho: investigando variáveis motivacionais e organizacionais como suas preditoras. Revista de Administração Contemporânea, Curitiba, v. 7, n. 4, p.77-96, 2003.

LIMA, S.M.V.; BORGES-ANDRADE, J.E. Bases conceituais e teóricas de avaliação de necessidades de treinamento. In: BORGES-ANDRADE, J.E.; ABBAD, G.S.; MOURÃ̃O, L.

REAd | Porto Alegre - Edição 79 - N 3 - setembro/dezembro 2014 - p. 740-772 
(Ed) Treinamento, desenvolvimento e educação em organizações e trabalho: fundamentos para gestão de pessoas. Porto Alegre: Artmed, 2006, p. 199-215.

MAGALHÃES, M. L.; BORGES-ANDRADE, J. E. Auto e Hetero-Avaliação no Diagnóstico de Necessidades de Treinamento. Estudos de Psicologia, Natal, v. 6, n.1, p.35-50, 2001.

MCCLELLAND, S.B. Training needs assessment: an "open-systems" application. Journal of European Industrial Training, London, v. 17, n.1, p. 12-17, 1993.

MCGEHEE, W.; THAYER, P.W. Training in business and industry. New York: Wiley, 1961.

MENESES, P. P. M.; ZERBINI, T. Levantamento das análises de treinamento: reflexões atuais. Análise, Porto Alegre, v. 20, n. 2, p. 50-64, 2009.

MENEZES, L.A.;RIVERA, R.C.P.; BORGES-ANDRADE, J.E. Necessidades de treinamento de agricultores e de suas mulheres num projeto integrado de colonização. Cadernos de Difusão de Tecnologia, Brasília, v.5, n.1, p.109-118, 1988.

MILES, J.; SHEVLIN, M. Applying Regression and Correlation: a guide for students and researchers. London: Sage Publications, 2001.

MOCELIN, D. G.; SILVA, L. F. S. C. O telemarketing e o perfil sócio-ocupacional dos empregados em call centers. Cadernos $C R H$, Salvador, v. 21, n.53, p. 361-383, 2008.

MOURÃO, L.; MARINS, J. Quem está motivado para aprender com as ações de treinamentos empresariais?. Paidéia-USP, Ribeirão Preto, v. 20, n.46, p. 187-196, 2010.

OMMANI, A.R.; CHIZARI, M. Analysis of the Training Needs of Agricultural Extension Experts Associated with Environmental Security in Agriculture. Research Journal of Environmental Sciences, New York, v. 3, n. 5, p. 594-598, 2009.

OSTROFF, C.; FORD, K. Introducing a Levels Perspective to Training Needs Assessment. In Goldstein, I. (Ed.), Training and Career Development. San Francisco: Jossey Bass, 1989, p. 25-62.

PILATI, R. Modelo de efetividade do treinamento no trabalho: aspectos dos treinandos e moderação do tipo de treinamento. Tese de Doutorado em Psicologia. Universidade de Brasília. Brasília, 2004.

REAd | Porto Alegre - Edição 79 - N 3 - setembro/dezembro 2014 - p. 740-772 
ROCHA, F.E.C; LEAL, B.N.; ABBAD, G. Necessidade de Treinamento e Planejamento Instrucional: Uma Experiência na Embrapa Cerrados. Brasília: Embrapa, 2002.

SALAS, E.; CANNON-BOWERS, A. The science of training: a decade of progress. Annual Review of Psychology, Palo Alto, CA, v. 52, n. 1, p. 471-499, 2001.

SALLORENZO, L. H. Avaliação do impacto de treinamento no trabalho: analisando e comparando modelos de predição. Dissertação de Mestrado em Psicologia. Universidade de Brasília. Brasília, 2000.

SANTOS, S.; MESQUITA, I.; GRAÇA, A.; ROSADO, A. Coaches' perceptions of competence and acknowledgement of training needs related to professional competences. Journal of Sports Science and Medicine, Bursa, v. 9, p. 62-70, 2010.

SCOLARI, C.; COSTA, S. G.; MAZZILLI, C. Prazer e sofrimento entre os trabalhadores de Call Center. Psicologia USP, São Paulo, v.20, n. 4, p. 555-576, 2009.

SILVA, G. G. da; MENESES, P. P. M. Necessidades de treinamento organizacional e motivação para trabalhar. REAd - Revista Eletrônica de Administração, Porto Alegre, v.18, n.1, p. 27-62, 2012.

SULLIVAN, S.E.; BARUCH, Y. Advances in Career Theory and Research: A Critical Review and Agenda for Future Exploration. Journal of Management, London: Sage Publications, v. 35, n.1, p. 1542-1571, 2009.

TABACHINICK, B. G.; FIDELL, L. S. Using multivariate statistics. (5th ed.) New York: HarperCollins, 2007.

THARENOU, P. The relationship of training motivation to participation in training and development. Journal of Occupational and Organizational Psychology, London: British Psychological Society, v. 74, n. 5, p. 599-621, 2001.

TSAI, W-C.; TAI, W-T. Perceived importance as a mediator of the relationship between training assignment and training motivation. Personnel Review, London: Emerald Group Publishing Limited, v. 32, n. 2, p. 151-163, 2003.

VASCONCELLOS, L.H.R. A contribuição do call center para a inovação em empresas prestadoras de serviços. Tese de Doutorado em Engenharia da Produção. Universidade de São Paulo. São Paulo, 2010.

REAd | Porto Alegre - Edição 79 - N 3 - setembro/dezembro 2014 - p. 740-772 
VERAS, V. S.; FERREIRA, M. C. Lidar com gente é muito complicado: relações socioprofissionais de trabalho e custo humano da atividade em teleatendimento governamental. Revista Brasileira de Saúde Ocupacional, São Paulo, v. 31, n.114, p. 135148, 2006.

VILELA, L. V. O.; ASSUNÇÃO, A. A. Os mecanismos de controle da atividade no setor de teleatendimento e as queixas de cansaço e esgotamento dos trabalhadores. Cadernos de Saúde Pública, Rio de Janeiro, v. 20, n. 4, p.1069-1078, 2004.

VROOM, V. H. Work and motivation. New York: Wiley, 1964.

WARR, P.; ALLAN, C.; BIRDI, K. Predicting three levels of training outcome. Journal of Occupational and Organizational Psychology. London: British Psychological Society, v.72, n. 3, p. 351-375, 1999.

WEXLEY, K. N. Personal Training. Annual Review of Psychology, Palo Alto, CA, v. 35, p. 519-551, 1984. 